\title{
SIMULATION OF HEAT TRANSFER IN A HEAT PIPE WITH AN AIR COOLED FINNED CONDENSER
}

\author{
RAQEEB H. RAJAB ${ }^{1}$ \& HUSSAIN H. AHMAD ${ }^{2}$ \\ ${ }^{1}$ Lecturer, Department of Agricultural Machines and Equipment, University of Mosul, Mosul, Iraq \\ ${ }^{2}$ Assistant Professor, Madenat Alelem University College, Baghdad, Iraq
}

\begin{abstract}
Computational fluid dynamics (CFD) analysis has been carried out to predict the overall temperature distribution of twophase thermosiphon, considered in the present study, and applied to experimental results under steady state conditions for three different heat inputs and two different working fluids with 50\% filling ratio. In a thermosiph on or wickless heat pipe, the high heat transfer rate is due to the latent heat of evaporation and latent heat of condensation. The heat transfer coefficient (HTC) increases with the increase of the heat input. Results show that using pure fluid is more effective mixture. Comparison between results of the present work and a theoretical correlation of other researchers shows a good agreement, especially in the case of pure fluid. The predicted temperatures when using theoretical (CFD)are good with that of experimental results.
\end{abstract}

KEYWORDS: Thermosiphon, Heat Pipe, Finned Condenser, Computational Fluid Dynamics

Received: Feb 29, 2020; Accepted: Mar 19, 2020; Published: May 12, 2020; Paper Id.: IJMPERDJUN202045

\section{INTRODUCTION AND LITERATURE REVIEW}

Because of the complex nature of the two phase flow, the problem was first approached by empirical methods. Despite its apparent simplicity, the annular configuration is very complicated in detail which reflects the great uncertainties in the prediction of the performances of annular two-phase system. The interface of the film is covered by complex system of waves, whose behavior is a governing feature [1]. Thermosiphon is heat transfer device capable of high heat transfer with small temperature gradient over the large distance [2].

The heat pipe (thermosiphon) is simple equipment used to transfer heat from one point to another in very effective way. It has many advantages such as it is mainly a closed tube with or without wick containing a small amount of liquid as a working fluid. There is no rotating parts so it doesn't require maintenance, it is not expensive and moreover it is very effective tool to transfer heat from one point (source) to another one (sink) with small different of temperature between the two points. If here is no wick inside the het pipe, it is known as a (thermosiphon). In general, it consists of three parts; the evaporator where liquid evaporates due to supplied heat and the condenser, where vapour condenses and the two parts are separated by an adiabatic section.

Modeling by CFD of flow and heat transfer in a heat pipe [3], gain intensive and deep attention of numbers of researchers.

ZHU Hua, et al, [3] carried out an experimental system measuring the pressure, temperature, heat transfer rate and mass flow rate in a semi-open two-phase thermosiphon. AL-Saadi Z., [4] carried out an experimental work measuring the heat transfer performance of a heat pipe (without wick) for residential heating. Test and analytical estimates performed by Shiraishi, M., et al [5]. To predict the performance of two-phase closed thermosiphon, the 
heat transfer characteristics were experimentally studied, followed by mathematical models. The flat two-phase thermosiphon characters were experimentally studied by Zhang, M., et al [6]. Different working fluids with different heat fluxes were used to measure the activity of the heat pipe.JiaoB.,etal [7] developed a numerical model showing the ratio influence of working charging on the performance of a vertical two-phase closed thermosiphon at steady-state conditions.

Because the thermosiphon is very effective in transferring heat with low cost, it has been used in different applications of a cooling system, as a heat-exchange in many industrial and electronic applications. It is used in heat recovery and so on. Since the processes inside the thermosiphon are very complex and different phenomena occur inside it such as evaporation, condensation, and two-phase flow, it is difficult to describe how they interact with each other, CFD modeling was used to simulate these processes. The results obtained from CFD were compared with experimental results to see the degree of agreement between the two types of results.

\section{OPERATION PRINCIPLE OF THERMOSIPHON}

As maintained before, the principle of thermosiphonoperation can be summarized as follows; when heat supplied to evaporator, the (working fluid) liquid absorbs heat and evaporates carrying latent heat and rise to the condenser via the adiabatic section due to the increase in pressure. The vapour condenses in the condenser rejecting heat to the cooling media. The condensate returns back, by gravity, to the evaporator and the cycle continues (with no capillary structure). For this reason, thermosiphon should be located vertically so that the evaporator is lower part. With this arrangement, there is no need to use a wick inside the thermosiphon since the gravity assists the return of the liquid.

\section{THERMOSIPHON TEST SECTION}

The thermosiphon is manufactured from cupper pipe with inside diameter $(13.5 \mathrm{~mm})$ and outside diameter $(15.5 \mathrm{~mm})$. The total length of the thermosiphon is $(600 \mathrm{~mm})$, divided into three sections; the evaporator is heated by Input power ranged from $(150 \mathrm{~W})$ to $(250 \mathrm{~W})$ with an interval of $(50 \mathrm{~W})$. Air was used to cool the condenser section with velocity ranged between $(0.24$ to $0.25 \mathrm{~m} / \mathrm{s})$. The working fluid use (pure water, pure acetone and mixture ratios $50 \%$ acetone/mixture In order to measure the average temperature of the thermosyphon, thermocouples were inserted into the outside surface of the heat pipe along its total length,(see Table 1); dimensions of the apparatus, and Figure [1] shows a schematic diagram of the test.

\begin{tabular}{ll}
\hline SPECIFICATIONS & DESCRIPTION, DIMENSIONS \\
\hline Material of heat pipe & Copper tube \\
\hline Total length & $600 \mathrm{~mm}$ \\
\hline Length of evaporator & $200 \mathrm{~mm}$ \\
\hline Length of adiabatic & $100 \mathrm{~mm}$ \\
\hline Length of condenser & $300 \mathrm{~mm}$ \\
\hline Fin geometric & Fin thickness: $0.5 \mathrm{~mm}$ \\
description. & Inside diameter: $15.5 \mathrm{~mm}$ \\
\hline Power Input & Outside diameter: $145 \mathrm{~mm}$ \\
\hline Air flow & $150 \mathrm{~W}-250 \mathrm{~W}$ \\
\hline Air velocity & $0.02 \mathrm{~m} 3 / \mathrm{s}$ \\
\hline Working Fluid & 0.24 to $0.25 \mathrm{~m} / \mathrm{s}$ \\
\hline Filling ratios & Pure acetone; Pure water \\
\hline \multicolumn{1}{c}{ Table 1: Specifications of thermosiphon. }
\end{tabular}




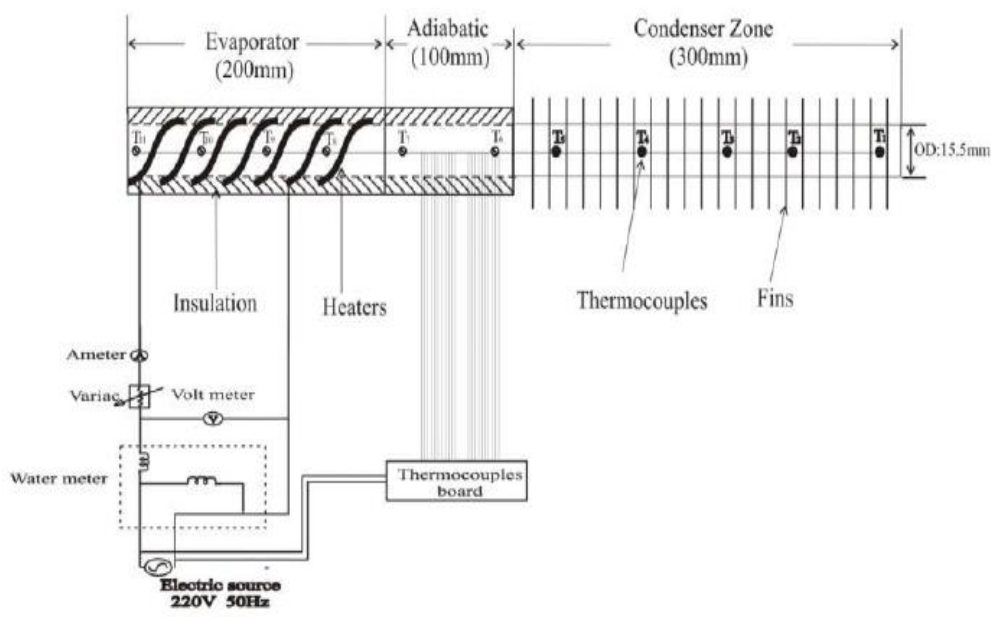

Figure 1a: Thermosiphon structure.

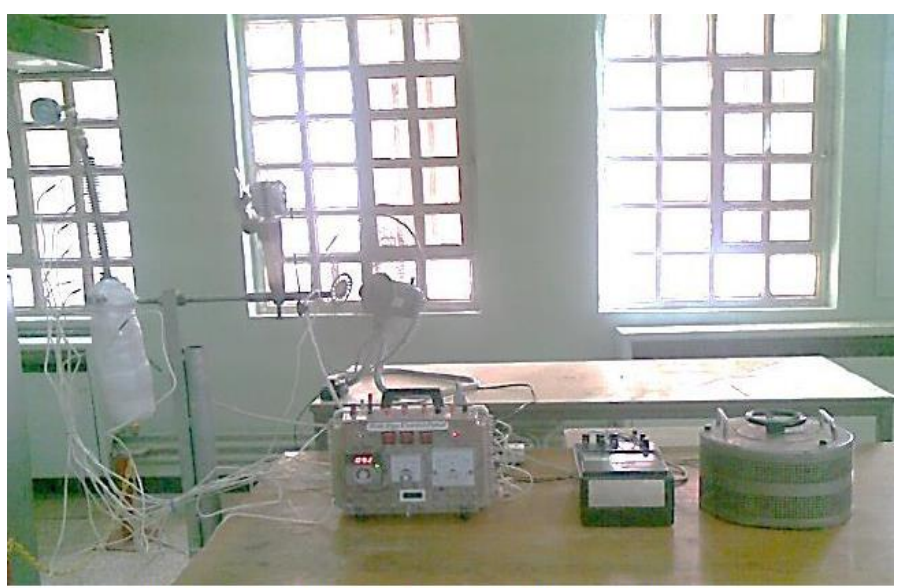

Figure 1b: A photograph showing the thermosiphon test rig.

\section{COMPUTATIONAL ANALYSIS}

\section{1.Equations Governing the Process}

The conjugate heat transfers and the fluid flow inside the heat pipe construction were mathematical rules. Steady-state continuity, momentum (Navier-StokesEquation), and energy equations were solved. Laminar incompressible flow considered.In the CFD modeling, theNavier-StokesEquationis doing simultaneously. These equating are:

$$
\begin{array}{lr}
\frac{\partial}{\partial t}(\rho)+\sum_{j=1}^{3} \frac{\partial}{\partial x_{j}}\left(\rho u_{j}\right)=S_{M} & \text { Continuity equation } \\
\frac{\partial}{\partial t}\left(\rho u_{j}\right)+\sum_{j=1}^{3} \frac{\partial}{\partial x_{j}}\left(\rho u_{i} u_{j}\right)=-\frac{\partial p}{\partial x_{i}}+\sum_{j=1}^{3} \frac{\partial}{\partial x_{j}}\left[\mu\left(\frac{\partial u_{i}}{\partial x_{j}}+\frac{\partial u_{j}}{\partial x_{i}}-\frac{2}{3} \delta_{i j} \sum_{i=1}^{3} \frac{\partial u_{i}}{\partial x_{j}}\right)\right]+S_{F, i} \text { Momentum equation... } \\
\frac{\partial}{\partial t}(\rho E)+\sum_{j=1}^{3} \frac{\partial}{\partial x_{j}}\left(\rho E u_{j}\right)=\sum_{i=1}^{3} \sum_{j=1}^{3}\left(\frac{\partial}{\partial x_{j}}\left(\tau_{i j}\right) u_{i}\right)-\sum_{i=1}^{3} \frac{\partial}{\partial x_{j}} q_{i}+S_{E} & \text { Energy equation ... }
\end{array}
$$

The properties $(\rho, \mu)$ of the fluid on the preceding equations depend on the $(\alpha \mathrm{k})$, and they were determined using the following equations 4,5 , and 6 :

$\rho=\sum_{\mathrm{k}=1}^{2} \alpha_{\mathrm{k}} \rho_{\mathrm{k}} \cdots$ 


$$
\begin{aligned}
\mu & =\sum_{\mathrm{k}=1}^{2} \alpha_{\mathrm{k}} \mu_{\mathrm{k}} \cdots \\
\mathrm{E} & =\frac{\sum_{\mathrm{k}=1}^{2} \alpha_{\mathrm{k}} \rho_{\mathrm{k}} \mathrm{E}_{\mathrm{k}}}{\sum_{\mathrm{k}=1}^{2} \alpha_{\mathrm{k}} \rho_{\mathrm{k}}} \ldots
\end{aligned}
$$

\section{Where;}

$\mathrm{E}_{\mathrm{k}}$, for each phase is based on the specific heat of that phase and the shared temperature. The interface between two phases is tracked by the volume fraction.

$\alpha$, represented by the interface mass balance using the following equation [8]:

$$
\frac{\partial \alpha}{\partial \mathrm{t}}+\mathrm{u} \cdot \nabla \alpha=0
$$

\subsection{Computation Fluid Dynamics (CFD)}

Computation fluid dynamics, CFD, is a very effective program used numerical algorithms methods to solve and analyzed complex problems related to fluid flow and heat transfer.It's one part of fluid mechanics applying analytical algorithms to solve also analyze complex problems related to fluid flow and heat transfer. In the application now, computational fluid dynamics (CFD) systems are popularly employed as a means of heat analysis. The mathematical solver principles are fully built and so give a good start to extra complicated heat transfer and fluid flow problems. The primary base of all CFD problems is theNavier-Stokes Equations, which describe eachsingle phasefluid flow. A gas/liquid two-phase flow, simultaneous evaporation and condensation phenomena in a thermosiphonwere simulated in this work. The experiments were conducted using different operating conditions, which are mentioned in the next section. Predicted and measured CFDtemperatures in the thermosiphonwere compared, which were resulted in a significant agreement between them. This observation confirmed that the CFD was beneficial means via simulated and demonstrates the complicated flow and heat transfer in a heat pipe.

\subsection{Boundary Condition}

The calculations are performed according to the following conditions:

- Condenser is cooled by air blower (forced convection).

- The thermosiphonis in vertical position with condenser is the upper part and evaporator is the lower part.

- Fixed temperature is applied at evaporator side.

- No slip condition is applied at adiabatic zone.

\section{For Calculation}

- $\quad$ For meshing, elements were used.

- Numbers of elements were about 11100 and more than 13500 nodes.

An initial amount of vapour fraction leaving the evaporator is assumed by the program to give a certain amount of mass flow, and hence the pressure drop is calculated in the thermosiphon. If the total pressure drop is not balanced with the 
net liquid head, anew amount of vapour fraction is selected and iteration continues until a final balance is reached, and the heat transfer in the thermosiphon is calculated.

The flow within heat pipe is simulated, through the experiential data results were obtained to calculate the heat transfer coefficient (HTC)[9], and the Labuntsov empirical correlation[10], was applied for calculating the heat transfer coefficient (HTC) using the engineering equation solver (EES results ), and a computer program written (established) in CFD with the help of following equations:

\section{Labuntsov empirical Correlation is:}

$$
H T C_{\text {Lab. }}=C\left[1+10\left(\frac{\rho_{v}}{\rho_{\ell}-\rho_{v}}\right)^{2 / 3}\right]\left(\frac{k^{2}}{v \sigma\left(T_{S}+273.15\right)}\right)^{1 / 3} \times q^{2 / 3}-
$$

\section{Experimental Heat Transfer Coefficient is}

$$
H T C_{\text {exp. }}=\frac{Q_{i n}}{\pi \times O D \times L \times\left(T_{e}-T_{a d}\right)}-
$$

\section{RESULTS AND DISCUSSIONS}

A CFD model built for the heat transfer simulating in the thermosiphon. The results show the relationship between heat transfer and temperature. The effect of heat input, type of liquid and the fill ratio on the performance of the thermosiphon were investigated in this study. It is clear; while the power load rises the performance is increasing. Additionally, pure water, pure acetone, and $50 \%$ mixture of water/acetone tests were carried out at three power inputs ranging from $(150,200$, and $250 \mathrm{~W})$.

The relationship between the data of the heat transfer coefficients from the present work, CFD, and Labuntsov correlation [10] at the above conditions is shown in figure 2. From the figure, it can be noted that the variation of the heat transfer coefficient for pure water and pure acetone at different heat loads, as the power load positive with the heat transfer coefficient.Generally, water has the highest heat transfer coefficient (experimentally and theoretically). The higher heat transfer coefficient HTC is obtained when pure water and pure acetone were used separately as working fluids. While addition of acetone to water decreases the value of heat transfer coefficient as it is noticed when a mixture is used as a working fluid having a ratio of $50 \%$. The deviation is due to that this correlation is based on data that covers nucleate pool boiling performed on this work of thermosiphon. In general, the comparison between the results of the experimental data and the analytical model, with another empirical correlation of Labuntsov shows an acceptable agreement. with labuntsov correlation results at different power inputs for various mixture ratio of fluids. 


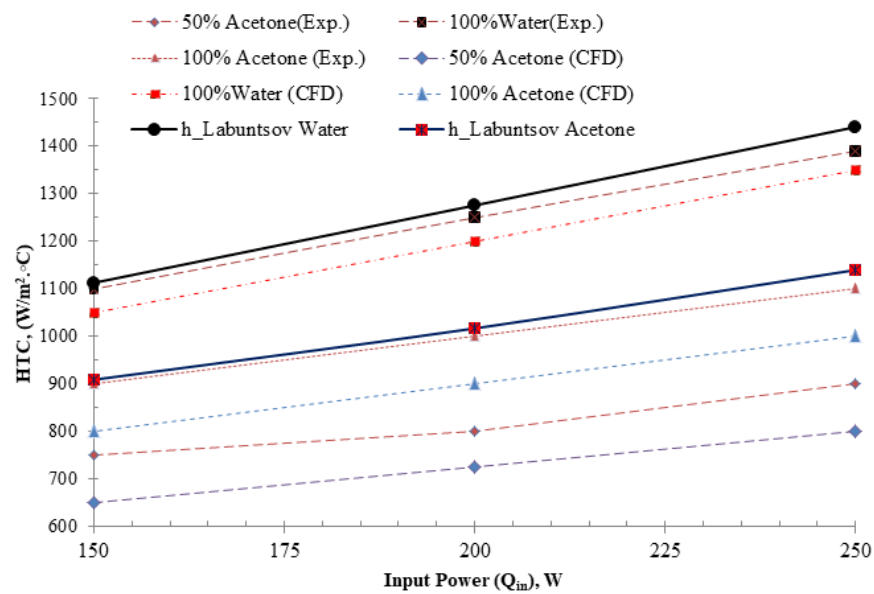

Figure 2: Comparison of the Experiment Heat Transfer Coefficient (HTC) and Theoretical CFD.

The variation of heat pipe (HP) temperature distribution through the distance from the bottom end of (HP) for pure water shown in figure 3 . The temperature starts increasing slightly to reach a maximum value at the evaporator, and then it begins to decrease through the rest part of the evaporator and adiabatic sections. The temperature decreases sharply at the condenser section and remains almost constant along it. The temperature profile is the same for all power inputs but values of temperature increase as the power inputs increase. The observations showed a significantly higher temperature at the evaporator decreased stability in temperature as the fluid passes through the adiabatic and condenser region. Moreover, the wall temperature in the evaporation part was more affected by raising the inlet heat flow compared to the adiabatic and condensation parts. Despite the theoretical results reported an insignificant heat loss in adiabatic zone, practically, there was a difference in heat loss in this particular section. Based on these outcomes, an acceptable agreement is noted between the two studied observations.

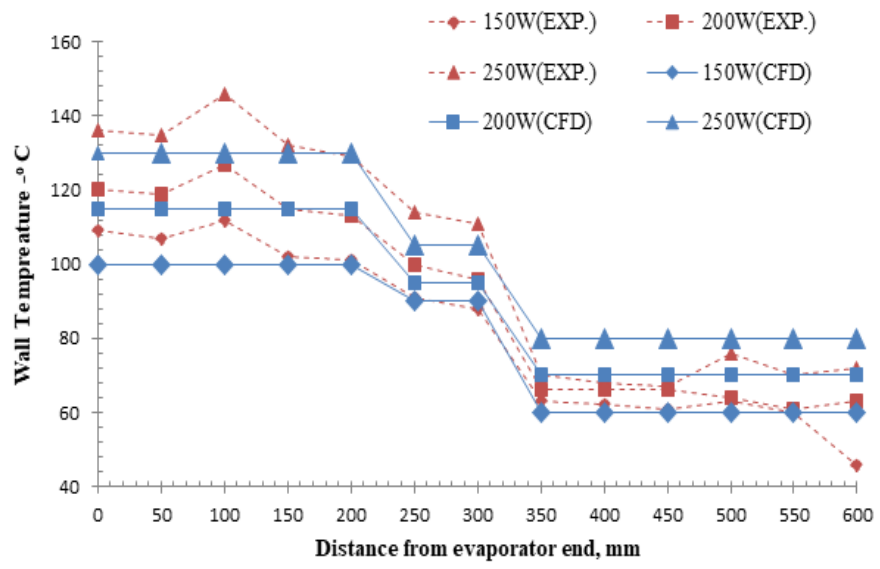

Figure 3: Variation of HP Wall Evaporator Temperature vs. Distance at Pure Water for Different Power.

Figure 4 presents the difference of (HP) surface temperature through the (HP) length at different heat input with a comparison between the experimental results and the CFD results for pure acetone as a working fluid. From the curves in the figure, it can be noted that the wall temperature calculated by CFD is higher, in general, than that experimentally obtained. This is because, in experiments, there are heat losses from the (HP) wall, which is uncounted when using CFD. Heat losses practically decrease the temperature. 


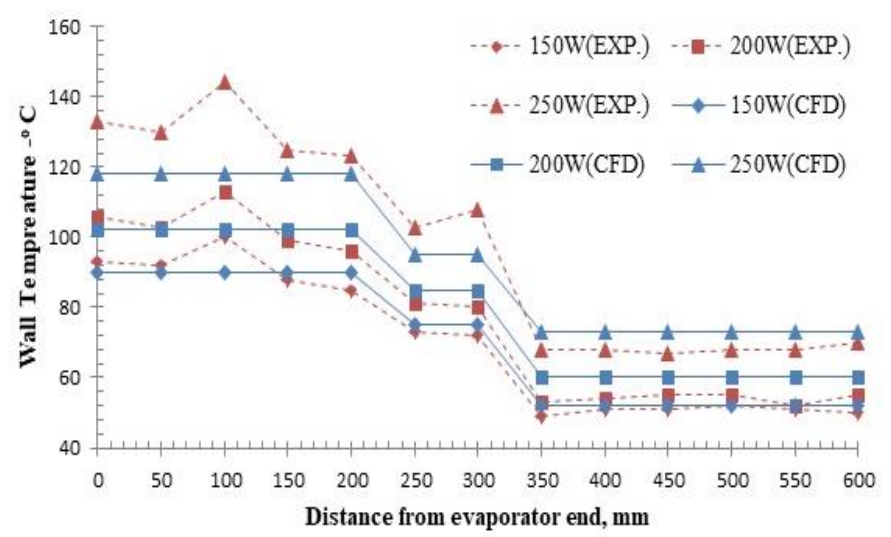

Figure 4: Variation of HP Wall Temperature vs. Distance at Pure Acetone for Different Power Input.

Figure (5) appears the distribution of the surface temperature at various heat input with 50\% acetone/water mixture as working fluid (experiment and CFD results).As seen in Figure 4 before, the CFD results are higher than that of experimental results for the same reason which is heat losses. But still in all cases under study, there is good agreement between experimental and CFD results.

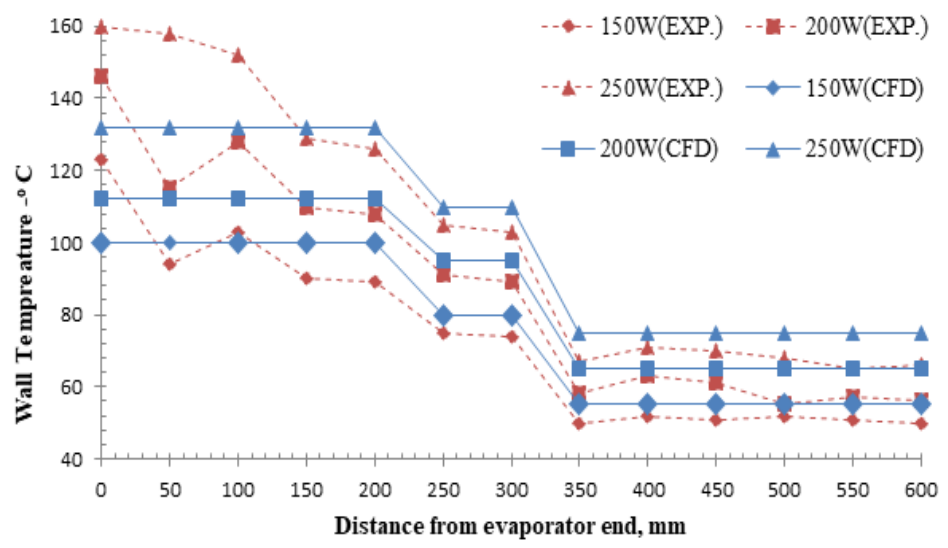

Figure 5: Variation of HP Wall Temperature vs. Distance at 50\% Acetone for Different Power Input.

Due to unpredicted and unknown mechanisms that can happen inside the heated pipe, it is hard to be clearly demonstrated. However, the fluctuated temperature can be attributed to the level of the liquid pool; which was increased in the evaporator temporally through returning the condensate flow from the condenser till a required level is achieved. Then the vapour moves to the condenser, until it forms a plug there. When the weight of the plug increased to a certain level, the vapor returns back to the evaporator. The vapor exchange between evaporator and condenser causes unstable temperature even during the thermosiphon steady state operation [4]. Another important point should be noted from all figures that the curves of CFD behavior are steadier than that of experimental results, which are fluctuated along the HP wall. This meanly because in CFD calculation, a steady state condition was considered while in experiment result, it is very difficult to keep the process under steady state. Again, this can be referred to the complex mechanism of the process inside HP in addition to the heat losses from HP, which is also affected to some extent by the environmental conditions.

\section{CONCLUSIONS}

The simulation results showed the following conclusions: 
- As the heat input increases, the heat transfer coefficient increases for both; experimental and CFD results.

- Temperature distribution along the thermosiphon obtained by CFD is more stable, compared to that of experimental data, because in experiments, there are many processes with complicated phenomena which are unaccounted in CFD results.

- In experiential results, the temperature is lower than that of CFD results along the adiabatic and condenser sections due to the effect of heat losses.

- The HTC is highest when the working fluid is pure water in both results (CFD and experimental)

- In general, the results of the analytical predictions show an acceptable agreement with data and the Labuntsov empirical correlation.

\section{ACKNOWLEDGMENT}

The author is thankful for the University of Mosul/ faculty of Engineering for their contributing and supporting to this work.

\begin{tabular}{|c|c|c|c|c|}
\hline Symbol & Meaning & Unit & \multicolumn{2}{|c|}{ Greek Letters } \\
\hline HTC & heat transfer coefficient & $\mathrm{W} / \mathrm{m}^{2} \cdot{ }^{\circ} \mathrm{C}$ & lab. & Labuntsov \\
\hline $\mathrm{C}$ & Constant, $\mathrm{C}=0.04$ for water & l & exp. & Experimental \\
\hline k & Thermal conductivity & $\mathrm{W} / \mathrm{m}^{\circ} \mathrm{C}$ & $\alpha$ & the interface mass balance \\
\hline $\mathbf{L}$ & Evaporator length & m & $\mathbf{O}$ & Outside \\
\hline D & Outside diameter & $\mathrm{m}$ & in & Input \\
\hline$q$ & Heat flux & $\mathrm{W} / \mathrm{m}^{2}$ & e & evaporator \\
\hline Q & power & W & ad & adiabatic \\
\hline $\mathrm{T}$ & temperature & ${ }^{\circ} \mathrm{C}$ & s & Saturation \\
\hline$\mu$ & dynamic viscosity & $\mathrm{Kg} / \mathrm{m} . \mathrm{s}$ & 1 & Liquid \\
\hline $\mathbf{v}$ & kinematics viscosity & $\mathrm{m}^{2} / \mathrm{s}$ & $\mathbf{v}$ & Vapor \\
\hline$\rho$ & density & $\mathrm{kg} / \mathrm{m}^{3}$ & $\mathbf{x}$ & volume fraction phase \\
\hline$\sigma$ & Surface tension & $\mathrm{N} / \mathrm{m}$ & $\alpha \mathbf{k}$ & volume fraction of each phase \\
\hline $\mathbf{E}$ & total energy per unit mass & $\mathrm{J} / \mathrm{kg}$ & oij & Kronecker function \\
\hline $\mathbf{P}$ & pressure & $\mathrm{Pa}$ & $\mathbf{k}$ & phase $\mathrm{k}$ \\
\hline SE & energy source term & $\mathrm{J} / \mathrm{m}^{3} \mathrm{~s}$ & j & xj-direction component \\
\hline SF & momentum source term & $\mathrm{kg} / \mathrm{m}^{2} \mathrm{~s}^{2}$ & & \\
\hline SM & mass source term & $\mathrm{kg} / \mathrm{m}^{3} \mathrm{~s}$ & & \\
\hline $\mathrm{t}$ & time & s & & \\
\hline $\mathrm{u}$ & velocity & $\mathrm{m} / \mathrm{s}$ & & \\
\hline
\end{tabular}

\section{REFERENCES}

1. Basim. O. Hasan, (2014). "Heat Transfer Analysis in Annular Two Phase Flow Using Finite Difference Method ", Journal of Petroleum Research, P. E71-E99.

2. Nikhil E. Chaudhari, Nishtha Vijra, T. P. Singh, (2013). "Computational Fluid Dynamics Analysis of Two-Phase Thermosyphon", International Journal of Engineering and Technology (IJET), ISSN: 0975-4024 Vol. 5 No 5 Oct-Nov, P. 3794

3. Benziger, B., P. Anu Nair, and P. Balakrishnan. "Review paper on thermoelectric airconditioner using peltier modules." IJME 4.

4. Hua, Z., Jian-Xin, W., Qiao-hui, Z. and Chuan-jing, T., "Experimental study on transient behavior of semi-open two-phase thermosyphon, "J. Zhejiang Univ. SCI (2004) 5(12):1565-1569.

5. AL-Saadi, Z., "Design and Implementing a Heat Pipe Experimental System for Residential Heating," M. Sc. Dissertation, 
Baghdad University, College of Engineering, (2005).

6. Senthilkumar, P. "ENVIRONMENTAL EFFECT OF USING DIESEL ON WASTE PLASTIC OIL FUELED IN DI DIESEL ENGINE. "International Journal of Mechanical Engineering (IJME) 7.3, (2018) 1-8

7. Shiraish, M., Kikuchi, K. and Yamanishi,T., "investigation of heat transfer characteristics of a two-phase closed thermosyphon," japane(1981).

8. Zhang, M., Liu, Z., and Ma, G., "The Experimental Investigation on Thermal Performance of a Flat Two-Phase Thermosyphon," Int. J. of Thermal Sciences 47, pp 1195-1203(2008).

9. Mansour, T. A., S. A. L. A. M. E. H. Sawalha, and N. E. S. R. E. E. N. Salem. "A Mathematical Model for Solar Assisted Automobile A/C Based on Absorption Refrigeration System." International Journal of Mechanical Engineering (IJME) 2.4 (2013): 75-86.

10. Jiao, B., Qiu, L. M., Zhang, X. B., and Zhang, y., "Investigation on the Effect of Filling Ratio on the Steady-State Heat Transfer Performance of a Vertical Two-Phase Closed Thermosyphon," Journal of Applied Thermal Engineering 28, pp 1417-1426, (2008).

11. Asghar Alizadehdakhel, Masoud Rahimi, Ammar Abdulaziz Alsairafi, "CFD modeling of flow and heat transfer in a thermosiphon", International Communications in Heat and Mass Transfer journal 37 (2010) 312-318

12. Geete, Ankur, and A. I. Khandwawala. "Exergy analysis for 120MW thermal power plant with different inlet temperature conditions." International Journal of Research in Engineering and Technology 2.1 (2014): 21-30.

13. Hussain H. Ahmad, (2012.)."Heat transfer characteristics in a heat pipe using water-hydrocarbon mixture as a working fluid (An Experimental Study)"Al-Rafidain Engineering Vol.20 No. 3

14. Labuntsov, "Heat Transfer Problems with Nucleate Boiling of Liquids", Thermal Engineering, 1972. 

